Missed Diagnosis

\title{
Angioma serpiginosum: a simulator of purpura
}

\author{
N.H. Cox and W.D. Paterson \\ Department of Dermatology, Cumberland Infirmary, Carlisle CA2 7HY, UK.
}

\begin{abstract}
Summary: We describe two patients with angioma serpiginosum who had both undergone a variety of haematological tests for investigation of purpura, but in whom careful examination of the skin demonstrated abnormal blood vessels rather than extravasated blood. Recognition of vascular disorders which simulate purpura may avoid unnecessary investigations.
\end{abstract}

\section{Introduction}

The range of disorders causing non-thrombocytopenic purpura ${ }^{1}$ includes abnormalities of platelet function, numerous causes of vessel wall inflammation (vasculitis), metabolic disorders such as amyloid and scurvy, and structural abnormalities of collagen. Several of these have clinical features in common, so patients with chronic purpura may be subjected to a broad range of investigations which are potentially time-consuming and expensive. It is therefore important to identify disorders in which the abnormality is not extravasation of blood but focal vascular prominence, acting as a simulator of chronic purpura. In the last six months, we have seen two patients with angioma serpiginosum who had been investigated for purpura, but in whom the skin lesions were demonstrably not purpuric on close clinical examination.

\section{Case reports}

\section{Case 1}

A woman, 35 years of age, was referred from the rheumatology department. She had a 1 year history of monoarthritis of the left knee, and a 4 year history of a fine 'petechial' or 'purpuric' rash which had also been investigated by the haematology department. Normal test results included full blood count, prothrombin time, partial thromboplastin time, erythrocyte sedimentation rate, platelet aggregation tests, and bleeding time. Normal or negative investigations for the arthropathy included R.A. latex, antinuclear and other antibodies

Correspondence: N.H. Cox, B.Sc., M.R.C.P. Accepted: 28 May 1991
(SS-A, SS-B, Sm and RNP), C-reactive protein, immunoglobulin levels, serum electrophoresis and serum urate. Examination of synovial fluid and synovial biopsy demonstrated only non-specific inflammation.

The 'purpuric' lesions were widespread, mainly on the trunk, small (most were $1 \mathrm{~mm}$ diameter) and difficult to blanch. The lesions were all the same red-purple colour, without evidence of haemosiderin deposition, and the blood content was clearly within capillary loops on close examination with a hand lens (Figure 1). There was no family history of similar lesions, and no involvement of mouth or fundi; although there were no annular or grouped lesions, angioma serpiginosum was thought to be the most appropriate diagnosis. As it was important to be firm about the lack of relationship between the skin lesions and the arthropathy, a skin biopsy was performed which confirmed the presence of clusters of dilated capillaries confined to the dermal papillae.

\section{Case 2}

A woman, 34 years of age, was referred from the haematology department. She had initially been seen in the urology department for investigation of loin pain, which had resolved spontaneously without a definite diagnosis, and recent onset of a 'petechial' rash had also been noted. The haematology department noted that some lesions were palpable, and she was referred to the dermatology department for investigation of a possible vasculitis. Full blood count, prothrombin time, partial thromboplastin time and platelet aggregation were normal. Dermatological examination demonstrated typical lesions of angioma serpiginosum as described above; skin biopsy was not performed. 
Figure 1 Multiple small skin lesions, each having several discrete dark puncta representing blood in ectatic capillaries.

\section{Discussion}

Angioma serpiginosum ${ }^{2-5}$ is an uncommon naevoid disorder of superficial dermal capillaries. It is usually sporadic but occasionally familial, most common in females, often most prominent on lower legs and buttocks, usually becomes apparent in late childhood, and is slowly progressive. This female predominance and teenage onset occurs in several naevoid disorders of skin blood vessels; and may indicate oestrogen dependence. The condition is asymptomatic and of no systemic significance although, like some other capillary disorders previously thought to be confined to the skin, ${ }^{6,7}$ there are occasional reports of involvement of other organs. ${ }^{8}$

The individual lesions are small red or purple puncta of about $1 \mathrm{~mm}$ diameter; they may be scattered, as in our patients, but are often grouped in vaguely annular or reticulate forms. The main differential diagnosis was from the tiny petechial lesions that can occur in patients with cherry angiomas (Campbell de Morgan spots); larger angiomas were not apparent in our patients, and although the small lesions have the same histological appearance as angioma serpiginosum they occur at a later age and are usually most apparent on the trunk. Although blanching by pressure can be difficult to demonstrate in small superficial angiomas, several features distinguish the lesions from chronic purpura. The initial clue is that all lesions are the same colour, whereas chronic purpura has a range of colours from bright red (freshly extravasated blood) to orange/brown (haemosiderin). Closer examination with a lens reveals that the lesions are made up of minute dots and streaks with pale areas between them, consistent with the histological demonstration that the abnormal vessels are virtually confined to the dermal papillae; the clinical features are therefore of intravascular rather than extravascular blood. Histological examination shows ectatic capillaries with abnormal structure, ${ }^{9}$ rather than the endothelial swelling and perivascular chronic inflammatory infiltrate expected in chronic purpuras. This disorder has previously been confused with chronic purpuras and differentiation from a group of 'pigmented purpuric dermatoses' has been discussed, ${ }^{4}$ however, the differential diagnosis should be from other angiomatous disorders such as hereditary haemor rhagic telangiectasia or Fabry's disease, rathe than from purpura. Although several of the invest gations in our first patient were prompted b $\vec{y}$ arthropathy rather than the 'purpura', numerous tests to evaluate the skin lesions had been performed previously; no vascular abnormalities were noted in the synovial biopsy and the arthropathy was apparently unrelated to the angioma serpiginosum. The distinction between purpura and structural abnormalities of blood vessels is important as careful clinical examination may obviate the need for numerous inappropriate investigations.

\section{References}

1. Champion, R.H. Purpura. In: Rook, A., Wilkinson, D.S., Ebling, F.J.G., Champion, R.H. \& Burton, J.L. (eds). Textbook of Dermatology, 4th ed. Blackwell Scientific Publications, Oxford, 1986, pp. 1109-1120.

2. Champion, RH. In: Rook, A., Wilkinson, D.S., Ebling, F.J.G., Champion, R.H. \& Burton, J.L. (eds). Textbook of Dermato$\log y$, 4th ed. Blackwell Scientific Publications, Oxford, 1986, pp. 1092-1093.

3. From, L. \& Assaad, D. In: Fitzpatrick, T.B., Eisen, A.Z., Wolff, K., Freedberg, I.M. \& Austen, K.F. (eds). Dermatology in General Medicine, 3rd ed. McGraw-Hill Book Co., New York, 1987, p. 1070.

4. Barker, L.P. \& Sachs, P.M. Angioma serpiginosum. Arch Dermatol 1965, 92: 613-620.
5. Frain-Bell, W.H. Angioma serpiginosum. Br J Dermatol 1957, 69: $251-268$.

6. Anderton, R.L. \& Smith, J.G. Unilateral naevoid telangiectasia with gastric involvement. Arch Dermatol 1975, 111: 617-621.

7. Cox, N.H. Arborizing telangiectasia with gastrointestinal involvement. Clin Exp Dermatol 1987, 12: 273-274.

8. Gautier-Smith, P.C., Sanders, M.D. \& Sanderson, K.V. Ocular and nervous system involvement in angioma serpiginosum. Br J Opthalmol 1971, 55: 433-443.

9. Lever, W.F. \& Schaumburg-Lever, G. Histopathology of the Skin, 6th ed. J.B. Lippincott Co., Philadelphia, 1983, p. 628. 